\title{
Low Inbreeding and High Pollen Dispersal Distances in Populations of Two Amazonian Forest Tree Species
}

\author{
Dominic Cloutier ${ }^{1,7}$, Olivier J. Hardy ${ }^{2}$, Henri Caron ${ }^{3}$, Ana Y. Ciampi ${ }^{4}$, Bernd Degen ${ }^{5}$, Milton Kanashiro ${ }^{6}$, and Daniel J. Schoen ${ }^{1}$ \\ ${ }^{1}$ McGill University, Department of Biology, 1205 Avenue Docteur Penfield, H3A 1B1, Montréal, QC, Canada \\ 2Université Libre de Bruxelles, Service d'Eco-Ethologie Evolutive, CP 160/12, 50 Avenue F. Roosevelt, B-1050 Brussels, Belgium \\ ${ }^{3}$ INRA, UMR BIOGECO, 69 Route d'Arcachon, 33610, Cestas, France \\ ${ }^{4}$ EMBRAPA-CENARGEN, Pq EB, Avenue W5 Norte, CP 02372, CEP 70770-900, Brasília, DF, Brazil
}

${ }^{5}$ Bundesforschungsanstalt für Forst- und Holzwirtschaft (BFH), Institut für Forstgenetik und Forstpflanzenzüchtung, Sieker Landstrasse 2, D-22927 Grosshansdorf, Germany

${ }^{6}$ EMBRAPA-Amazônia-Oriental, Trav. Dr. Enéas Pinheiro, s/n, Marco, CEP 66095-100, Belém, Pa, Brazil

\begin{abstract}
Recent studies suggest that tropical tree species exhibit low inbreeding and high gene dispersal levels despite the typically low density of conspecifics in tropical forests. To examine this, we undertook a study of pollen gene dispersal and mating system of two Amazonian tree species. We analyzed 341 seeds from 33 trees at four microsatellite loci in a Carapa guianensis population from Brazil, and 212 seeds from 22 trees at four microsatellite loci in a Sextonia rubra population from French Guiana. Differentiation of allele frequencies among the pollen pool of individual trees was $\Phi_{\mathrm{FT}}=0.053$ (95\% CI: 0.027-0.074) for $C$. guianensis and $\Phi_{\mathrm{FT}}=0.064$ (95\% CI: 0.017-0.088) for S. rubra. The mean pollen dispersal distances were estimated at 69-355 m for C. guianensis, and 86-303 m for $S$. rubra, depending on the pollen dispersal model and the estimate of reproductive tree density used. The multi-locus outcrossing rate was estimated at 0.918 and 0.945 , and the correlation of paternity at 0.089 and 0.096 , for C. guianensis and S. rubra, respectively, while no significant levels of biparental inbreeding were detected. Comparing trees with high and low local density of conspecifics, we found no evidence for differences in inbreeding levels. The results are discussed within the framework of the emerging picture of the reproductive biology of tropical forest trees.
\end{abstract}

Abstract in French is available at http://www.blackwell-synergy.com/loi/btp

Key words: Carapa guianensis; correlated paternity; mating system; microsatellite loci; Sextonia rubra; tropical wet forest; TwoGener.

EARLY PREDICTIONS ABOUT MATING AND POLLEN DISPERSAL IN TROPICAL TREE SPECIES were that relatively low population densities would lead to high levels of inbreeding and limited pollen dispersal due to restricted among-tree movement of pollinators (e.g., Baker 1959, Federov 1966). However, direct investigations of tropical tree breeding systems soon revealed that obligate outcrossing is the main mode of reproduction in tropical trees (e.g., Bawa 1974). Moreover, early studies based on mark-recapture experiments with pollinators and direct observations of pollinator flight patterns revealed that some pollinators of tropical trees forage over large distances and thereby may mediate pollen flow among widely spaced conspecific trees (Bawa 1990).

Genetic markers such as allozymes or microsatellites have been used recently to infer realized mating and gene flow patterns in tropical tree species. Such investigations have revealed that most tropical tree species are predominantly outcrossing (reviewed in Doligez \& Joly 1997, Nason \& Hamrick 1997, Loveless 2002, Ward et al. 2005), although a number of species investigated showed a significant proportion of progeny produced by selfing. Other genetic marker-based studies suggest that pollen movement is the

Received 16 January 2006; revision accepted 27 June 2006.

${ }^{7}$ Corresponding author; e-mail: dominic.cloutier@mail.mcgill.ca principal contributor to gene flow and can occur over large distances (reviewed in Nason \& Hamrick 1997). For instance, a paternity analysis unambiguously showed that animal-mediated movement of pollen can occur at a distance of $3.2 \mathrm{~km}$ (Dick 2001), but estimates of average pollination distances are usually in the range of a few hundred meters (reviewed in Nason \& Hamrick 1997, Loveless 2002). Other studies based on comparisons among populations suggest that pollen dispersal (Stacy et al. 1996, Degen et al. 2004) and selfing rate (Murawski \& Hamrick 1991, 1992) are negatively correlated with tree density. As well, comparisons of pollen flow in undisturbed and disturbed habitats suggest that larger among-tree distances resulting from habitat fragmentation lead to increases in pollination distances and enhance pollen flow (Chase et al. 1996, Dick 2001, White et al. 2002, Dick et al. 2003), though in some cases, artificial reduction of tree density by selective logging increases levels of self-fertilization (Murawski et al. 1994, Doliguez \& Joly 1997). Indirect estimates of historical gene dispersal distances also found a negative relationship with local population densities (Hardy et al. 2006).

Diverse factors such as the prevalence of animal pollination and the interactions between pollinator and plant populations, the diversity of breeding systems, the lack of seasonality of pollination at the community level, and the typically shorter longevity of the 
flowers may impact upon mating and gene flow patterns in tropical tree populations (Bawa 1990). Several authors have stressed the importance and possible application of understanding mating and gene flow patterns in the context of sustainable management of tropical forests (Bawa 1990, Ledig 1992, Kanashiro et al. 2002, Loveless 2002). Moreover, recently developed and powerful analytical tools are available (Austerlitz \& Smouse 2001, Smouse et al. 2001, Ritland 2002), but relatively few attempts have been made to apply these to studies of the mating system and gene dispersal in high biodiversity Amazonian forests.

Our aim was to examine the hypotheses that Amazonian tropical trees in continuous forests are highly outcrossing and effectively disperse their pollen over large distances. As such, we selected two canopy forest tree species, Carapa guianensis from Brazil and Sextonia rubra from French Guiana, sharing two ecologically relevant features: (1) an unspecialized pollination system based on small diverse insects, and (2) a high local population density ( $>1$ tree/ha) relative to other Amazonian tree species. In addition to these features, both species are commercially exploited for timber in the local and international markets, and as such, they are representative of many exploited tree populations. Our results are discussed within the framework of the emerging picture of the reproductive biology of tropical forest trees. Specifically, this paper examines the following hypotheses regarding these species: (1) tropical insect pollinators disperse pollen to other conspecifics over hundreds of meters, even though the small size of the pollinators suggests restricted betweentree movement; (2) tropical tree populations are largely outcrossing, and have limited opportunities for mating among relatives in natural settings, even though tropical tree species have sexual systems (i.e., hermaphrodite or monoecious) that enable self-fertilization; (3) a large number of fathers pollinate maternal parent trees in a single reproductive episode, even though factors such as population density and reproductive phenology suggest that near-neighbor mating may prevail; and (4) maternal parent trees with reduced local density of conspecific neighbors produce seed crops with higher levels of inbreeding, depending on the reproductive biology of the tree species.

\section{METHODS}

STUDY SPECIES AND STUDY SITES.-Carapa guianensis Aublet (Meliaceae) is a canopy tree species widely distributed in the Caribbean islands, Central America, and northern South America. It can reach $1 \mathrm{~m}$ in diameter at breast height (DBH) and 30-40 $\mathrm{m}$ in height. In the Brazilian Amazon, it is found in various habitats, from seasonally flooded river edges to dry uplands, and is occasionally planted by local indigenous and riverine communities where it grows. In Brazil, it is an important timber tree species, and the oil extracted from the seed is extensively traded and used for its medicinal properties.

Carapa guianensis is a monoecious species harboring both male and female flowers on the same tree. The flowers are small, white, and are found on conspicuous inflorescences. During several hours of observation on a few branches of a tree, small stingless bees, beetles, and moths have been seen in small numbers visiting the flowers in the morning (D. Cloutier, pers. obs.; M. Maues, pers. comm.), suggesting that it is pollinated by small insects. The fruit is a four-valved capsule containing 4-20 seeds weighting 20-40 $\mathrm{g}$ each. The seed may float on water and be dispersed over large distances in flood-prone forests (Scarano et al. 2003, Cloutier et al. 2005). In the upland terra firme populations, the seeds are dispersed by gravity and secondarily by medium-sized scatterhoarding rodents for distances less than $25 \mathrm{~m}$ (Guariguata et al. 2002). This species flowers intensively from August through May in the Tapajós river area, and fruits are released from January through July.

The study site for C. guianensis is Flona Tapajós $\left(03^{\circ} 01^{\prime} \mathrm{S}\right.$, $\left.54^{\circ} 58^{\prime} \mathrm{W}\right)$, Para state, Brazil. Under the auspices of the Dendrogene project (Kanashiro et al. 2002), an intensive study plot is currently being monitored within the Flona Tapajós. This is part of a larger, ongoing study focusing on genetic conservation in managed forests of Amazonia. Prior to this study, a commercial prelogging inventory was conducted in the study plot (500 ha), and every tree larger than $20 \mathrm{~cm} \mathrm{DBH}$ was identified and mapped. A mean density of 2.5 C. guianensis trees/ha $\geq 30 \mathrm{~cm} \mathrm{DBH}$ was found in the 400 ha of the central plot area (Fig. 1), indicating that C. guianensis has the second highest average tree density at this site.

Sextonia rubra (Mez) van der Werff (Lauraceae) is a canopy tree species reaching $1 \mathrm{~m} \mathrm{DBH}$ and $40 \mathrm{~m}$ in height. It is found in the Guyanas and the Eastern Amazon basin. It is one of the most intensely harvested timber tree species in French Guiana.

Plants of $S$. rubra produce small hermaphroditic, scented, white flowers in August and September in French Guiana. The pollinators of $S$. rubra have not been observed, but the size and the color of the flowers suggest that pollination is mediated by small insects (sensu Bawa et al. 1985). The fruits contain a single seed and are produced in January in French Guiana. It has been reported that the seeds are dispersed by birds (Hardy et al. 2006), but the bulk of seeds are released on the ground beneath the trees.

The study site for $S$. rubra is Paracou $\left(5^{\circ} 18^{\prime} \mathrm{N}, 52^{\circ} 53^{\prime} \mathrm{W}\right)$, French Guiana. Paracou is composed of 16 noncontiguous permanent study square plots (15 of 6.25 ha plus 1 of 25 ha; Fig. 1) administered since 1984 by CIRAD-Forêt (French Agricultural Research Centre for International Development-Forestry Department) to study forest regeneration under natural and logging conditions (Schmitt \& Bariteau 1988). All trees larger than $10 \mathrm{~cm} \mathrm{DBH}$ have been identified and mapped in the plots. A total of 154 S. rubra trees above $30 \mathrm{~cm} \mathrm{DBH}$ are found in the 119 ha of the Paracou plots, for an estimated average density of 1.3 trees/ha.

FIELD SAMPLING.-For C. guianensis, fruits were collected directly beneath 33 maternal parent (mother) trees between April and July 2003 at the Tapajós site. These trees were selected to provide a range of interindividual distances, from trees that are close enough to receive pollen from the same source trees, to those far apart and likely to receive pollen from different source trees. The intertree distances varied between $6 \mathrm{~m}$ and $1883 \mathrm{~m}$, averaging at $722 \mathrm{~m}$. The number of fruits collected from each tree varied from 8 to 13, for a grand total of 341 progeny analyzed. A separate genetic analysis conducted on C. guianensis multiseeded fruits collected in 
A

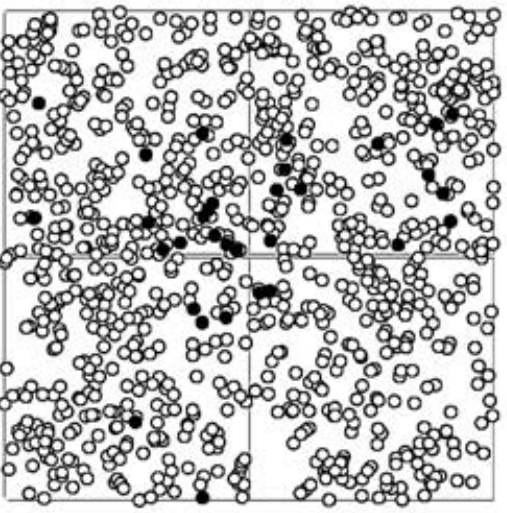

B

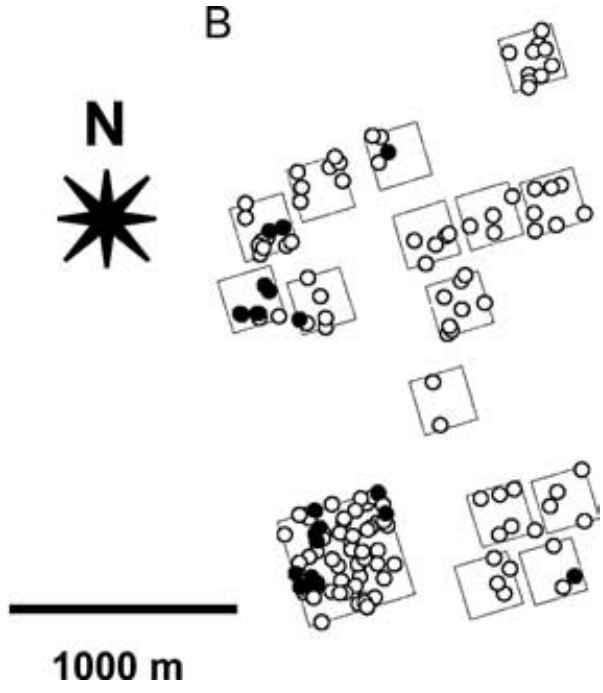

FIGURE 1. Distribution of (A) Carapa guianensis at Tapajos and (B) Sextonia rubra at Paracou with sizes $>30 \mathrm{~cm}$ DBH. For both sites, the plots are embedded within continuous forest for which the distribution of $C$. guianensis and S. rubra trees is not shown here. Filled circles are the trees from which seed was sampled.

2004 at Tapajós revealed that seeds within individual fruits are significantly more likely to share the same father than are seeds taken from different fruits of the same mother tree (D. Cloutier, pers. obs.), suggesting correlated pollen dispersal events (i.e., pollen codispersal from the same male parent(s) to single flowers). Thus, to sample as many independent pollination events as possible, only one seed per fruit was genotyped. In order to get information on the C. guianensis adult trees, a piece of cambium $(\sim 150 \mathrm{mg})$ was extracted from 199 trees with known spatial location, including or distributed around the mother trees from which seeds were collected. The cambium samples were stored in a buffer of 70 percent ethanol and 0.3 percent $\beta$-mercaptoethanol before being sent to the lab.

For S. rubra, single-seeded fruits were collected directly beneath mother trees in January 2000 at Paracou. Preliminary trials suggested that the DNA extracted from roots of germinated seedlings gave the best PCR results when used at low concentrations. Therefore, seeds were planted and the roots of the seedlings were collected and kept in the freezer until DNA extraction in 2002. Fewer seed genotypes were available than in the $C$. guianensis population-the final data set was composed of 212 seeds taken from 22 mother trees, with each of the 22 seed families containing between 2 and 15 seeds. For population level analyses of mating system, the 22 families were used, while only the 15 families with at least 8 seeds genotyped were used for pollen dispersal analyses. The intertree distances of the 15 families with at least 8 seeds genotyped varied between $33 \mathrm{~m}$ and $2128 \mathrm{~m}$, with a mean of $833 \mathrm{~m}$.

The maternal parent trees of the fruits collected on the ground were identified with certainty in most cases-at both sites, there was no evidence that fruits were previously handled by animals, and because large distances separate conspecific trees, the probability that seed shadows overlap is low. In a few cases, however, fruits could have been incorrectly assigned to a mother tree because of the proximity of a conspecific, or because of incorrect labeling of the fruits sampled. To rule out incorrect assignment of progeny to the mother trees, and to check the inheritance and segregation of alleles at the microsatellite loci used, we compared mother tree and seed genotypes to detect and remove mismatched individuals from the data set. Maternal parent genotypes were available from the adult tree sample of $C$. guianensis, while most maternal parent genotypes of $S$. rubra were known from another study (Hardy et al. 2006). The genotypes of the few trees missing were inferred from seed family genotypes (Brown \& Allard 1970).

LABORATORY ANALYSES. - Carapa guianensis cambium and seed samples were brought into the plant genetic laboratory of EMBRAPACENARGEN (Brazilian Agricultural Research CorporationCenter for Genetic Resources and Biotechnology) in Brasilia, Federal District, Brazil. The samples were ground in liquid nitrogen and total genomic DNA was extracted from cambium samples, fresh embryos, and dried leaves of germinated seed using a standard CTAB-chloroform-isoamyl alcohol protocol. Genotypes were scored at four microsatellite loci (i.e., $\mathrm{Cg} 1, \mathrm{Cg} 6, \mathrm{Cg} 16$, and $\mathrm{Cg} 17$ ), described by Vinson et al. (2005). The PCR amplification cocktail (total volume of $13 \mu \mathrm{l}$ ) contained: PCR reaction buffer (Invitrogen), forward (labeled with fluorescence) and reverse primer $(0.28 \mu \mathrm{M})$, $\mathrm{MgCl}_{2}(1.5 \mathrm{mM})$, BSA $(0.25 \mathrm{mg} / \mathrm{ml}), \mathrm{dNTP}(0.25 \mathrm{mM})$, Taq DNA polymerase (1.3 U, Invitrogen), and DNA ( $\sim 3 \mathrm{ng})$. PCR conditions were: denaturation at $94^{\circ} \mathrm{C}$ for $5 \mathrm{~min}$; 35 cycles of denaturation at $94^{\circ} \mathrm{C}$ for $1 \mathrm{~min}$, annealing at $53-59^{\circ} \mathrm{C}$ for $1 \mathrm{~min}$, and extension at $72^{\circ} \mathrm{C}$ for $1 \mathrm{~min}$, followed by a final extension at $72^{\circ} \mathrm{C}$ for $30 \mathrm{~min}$. Optimal annealing temperature and concentrations of primers, DNA template, and $\mathrm{MgCl}_{2}$ were adjusted empirically for each locus. Reaction products were separated by electrophoresis on an ABI 377 automatic sequencer (Applied Biosystems, Foster City, California, USA) jointly with a custom-made size standard. Genotypes were determined using the software Genotyper (Applied Biosystems). 
Sextonia rubra seed samples were brought to the laboratory of INRA (French National Institute for Agricultural Research) at Kourou, French Guiana, France. DNA was extracted using a standard CTAB-chloroform-isoamyl alcohol protocol from frozen roots of germinated seed grounded in liquid nitrogen. Genotypes were scored at four microsatellite loci (i.e., Sr3, Sr9, Sr10, and Sr51) developed by H. Caron (Veron et al. 2005). The PCR cocktail (10.0 $\mu \mathrm{l}$ total) contained reaction buffer (Invitrogen), $0.04 \mu \mathrm{M}$ of each dNTP, $0.01-0.04 \mu \mathrm{M}$ of $\mathrm{MgCl}_{2}, 0.5 \mathrm{U}$ of Taq DNA polymerase (Invitrogen), $0.001-0.01 \mu \mathrm{M}$ of each primer (forward primer labeled with fluorescence) and $\sim 0.2 \mathrm{ng}$ of DNA. The PCR protocol was: $5 \mathrm{~min}$ at $94^{\circ} \mathrm{C} ; 35$ cycles of $45 \mathrm{sec}$ at $94^{\circ} \mathrm{C}, 45 \mathrm{sec}$ at $55-60^{\circ} \mathrm{C}$, and $45 \mathrm{sec}$ at $72^{\circ} \mathrm{C}$; ending with $45 \mathrm{~min}$ at $72^{\circ} \mathrm{C}$. Optimal annealing temperature and concentrations of primers, DNA template, and $\mathrm{MgCl}_{2}$ were adjusted empirically for each primer pair. The amplification products were determined by electrophoresis with a ROX500 size standard on an ABI 310 automated sequencer (Applied Biosystems). Allele sizes were scored using the program Genotyper (Applied Biosystems).

Standard genetic diversity parameters were estimated from the seed samples for the microsatellite loci used with the program GENEPOP (Raymond \& Rousset 1995). Using the same program, no linkage disequilibrium among the $C$. guianensis loci was detected in the adult sample, while no sample was available to test this for $S$. rubra.

ADUlT GENETIC STRUCTURE ANALYSES.-The mating system and pollen dispersal analyses presented in this study require some knowledge of the genetic structure of the adult trees of each population. The adult tree sample of $C$. guianensis was analyzed, therefore, using the program SPAGEDI (Hardy \& Vekemans 2002) to estimate adult fixation index $\left(\mathrm{F}_{\mathrm{IS}}\right)$ and the statistic " $P p$." This statistic, based on the regression of genetic similarity between pairs of individuals over the natural logarithm of the physical distance separating them, allows quantitative comparison among species of the intensity of spatial genetic structure (SGS), and is described in detail by Vekemans and Hardy (2004). The standard error for $S p$ was obtained by jackknifing genetic loci and the $S p$ value was tested against the null hypothesis of random distribution of genotypes (i.e., no SGS) by permuting the spatial positions of the adults 1000 times. The genetic structure estimates of the $S$. rubra adult trees from Paracou are published elsewhere (Hardy et al. 2006) and gave a $F_{I S}$ of 0.076 , and a $S p$ value of 0.005 (0.001), indicating very weak (but statistically significant) SGS among the adult trees.

"TwOGENER" POLLEN DISPERSAL ANALYSES.-Pollen dispersal was analyzed with the "TwoGener" algorithm developed by Smouse et al. (2001) using a program obtained from F. Austerlitz (Université Paris-Sud, France). The statistic $\phi_{\mathrm{FT}}$, which measures the differentiation in allelic frequencies among the pollen clouds sampled by different seed parents whose spatial coordinates are known, was computed to estimate pollen dispersal parameters. The formal relationship between $\phi_{\mathrm{FT}}$ and pollen dispersal parameters has been derived for different pollen flow models (Austerlitz \& Smouse 2001). A global $\phi_{\mathrm{FT}}$, based on average pollen pool differentiation and average physical distance over all pairs of sampled mothers, or a pairwise $\phi_{\mathrm{FT}}$, based on pollen pool differentiation and physical distance between each pair of sampled mother, can be used to estimate pollen dispersal parameters.

First, we estimated the effective number of pollen donors contributing to the progeny of the average mother tree $\left(\mathrm{N}_{\mathrm{ep}}\right)$ - this is derived directly from the global estimate of $\phi_{\mathrm{FT}}$ as $\mathrm{N}_{\mathrm{ep}}=1 / 2 \phi_{\mathrm{FT}}$ (Austerlitz \& Smouse 2001, Smouse et al. 2001). Second, we estimated $\delta$ (i.e., the average distance of realized pollen dispersal) from the $\phi_{\mathrm{FT}}$ estimates (Austerlitz \& Smouse 2001, 2002; Austerlitz et al. 2004). The global estimate of $\phi_{\mathrm{FT}}$ from the whole set of sampled mother trees (Austerlitz \& Smouse 2001), or the pairwise estimates of $\phi_{\mathrm{FT}}$ between each pair of sampled mother tree (Austerlitz \& Smouse 2002, Austerlitz et al. 2004) are used to estimate $\delta$ by assuming an underlying density of reproducing trees $(d)$ and a pollen dispersal model (i.e., normal, exponential, or power exponential). Because $\mathrm{N}_{\mathrm{e}} / \mathrm{N}$ ratios in plant populations vary from values close to one, to values as low as $1 / 10$ (e.g., due to varying fertility and nonsynchronous flowering; Frankham 1995), we estimated $\delta$ from global $\phi_{\mathrm{FT}}$ assuming an upper bound estimate of the density of reproducing trees $\left(d_{\max }\right)$ (i.e., the global density of conspecific trees $>30 \mathrm{~cm} \mathrm{DBH}$ in the field), and a lower bound estimate of $d\left(d_{\min }=d_{\max } / 10\right)$. The pairwise $\phi_{\mathrm{FT}}$ can also be used to jointly infer $\delta, d$, and the shape of the pollen dispersal curve (i.e., whether the curve is exponential, thin-tailed and decreasing faster than the exponential, or fat-tailed and decreasing slower than the exponential). A least squares criterion is used to optimize the fit between observed pairwise $\phi_{\mathrm{FT}}$ values and those expected from the pollen dispersal model. The residual error for the different dispersal models tested can be compared to assess which provides the better fit to the data (Austerlitz et al. 2004). To assess the $95 \% \mathrm{CI}$ of the global $\phi_{\mathrm{FT}}$ dispersal estimates and the pairwise $\phi_{\mathrm{FT}}$ dispersal estimates based on the normal model, 100 bootstrap estimates were calculated using the seed families as the resampling unit. Because of the prohibitive amount of computer processing time required for the calculations, the bootstraps for the pairwise $\phi_{\mathrm{FT}}$ were not performed for the exponential and the power exponential model of pollen flow.

MATING SYSTEM ANALYSES.-The mating system analyses were done using the mixed-mating model with the MLTR program (Version 3.1, Ritland 2002). This program calculates maximum likelihood estimates of: (1) the rate of outcrossing; (2) the level of biparental inbreeding - this is estimated as the difference between multi- and single-locus estimates of outcrossing rate, using the fact that the likelihood of confusing selfed and biparentally inbred progeny is reduced when the number of loci used in the estimation increases; and (3) the correlation of paternity, i.e., the extent to which siblings share the same male parent. We assumed no apomixis and no seed mortality due to inbreeding prior to the assay. The MLTR program options were set to their default values, except that the parental fixation indices were constrained to values estimated from the adult tree samples (i.e., 0.029 for C. guianensis and 0.076 for S. rubra). The variance of the MLTR estimates was estimated by bootstrapping 1000 times at the level of seed family. 
Two types of mating system analyses were conducted. In the first type, we estimated the mating system at the level of the whole population. In the second type, we assessed the impact of withinpopulation variation in local density of conspecific neighbors on the mating system. To do this, we classified each mother tree into one of two groups: (1) trees with higher neighbor density than global density; and (2) trees with lower density of neighbors relative to the global density. "Neighbors" were defined as conspecific trees found within the average pollination distance of the mother trees, as estimated by TwoGener when effective density and pollen dispersal are jointly estimated. Since the study plots at the Paracou field site were small and not contiguous, estimates of neighbor density for S. rubra were based on individual plot tree density.

\section{RESULTS}

MicrosatelLITE LOCI.-Table 1 shows the allele frequencies, gene diversities $\left(\mathrm{H}_{\mathrm{e}}\right)$, observed heterozygosity $\left(\mathrm{H}_{\mathrm{o}}\right)$, and fixation indices $\left(\mathrm{F}_{\mathrm{IS}}\right)$ obtained with the four microsatellite loci used in each species. We detected high levels of gene diversity, varying between 0.42 and 0.83 for C. guianensis, and between 0.80 and 0.86 for S. rubra, indicating that the microsatellite loci diversity is adequate for mating

TABLE 1. Allele frequencies, number of seed genotyped $(\mathrm{N})$, gene diversity $\left(H_{e}\right)$, observed frequency of heterozygotes $\left(H_{o}\right)$, and fixation index $\left(F_{I S}\right)$ in microsatellite loci of Carapa guianensis and Sextonia rubra.

Carapa guianensis microsatellite loci Sextonia rubra microsatellite loci

\begin{tabular}{lccccccccc}
\cline { 8 - 9 } \cline { 7 - 8 } Allele & Cg1 & Cg6 & Cg16 & Cg17 & Sr3 & Sr9 & Sr10 & Sr51 \\
\hline 1 & 0.729 & 0.285 & 0.015 & 0.031 & 0.300 & 0.193 & 0.227 & 0.003 \\
2 & 0.215 & 0.054 & 0.011 & 0.034 & 0.008 & 0.050 & 0.002 & 0.065 \\
3 & 0.055 & 0.006 & 0.034 & 0.275 & 0.029 & 0.024 & 0.024 & 0.013 \\
4 & & 0.001 & 0.105 & 0.056 & 0.037 & 0.147 & 0.268 & 0.182 \\
5 & & 0.039 & 0.414 & 0.201 & 0.086 & 0.009 & 0.085 & 0.240 \\
6 & & 0.010 & 0.233 & 0.029 & 0.026 & 0.110 & 0.080 & 0.138 \\
7 & & 0.271 & 0.023 & 0.141 & 0.081 & 0.088 & 0.002 & 0.214 \\
8 & & 0.188 & 0.027 & 0.099 & 0.117 & 0.211 & 0.251 & 0.005 \\
9 & & 0.095 & 0.011 & 0.133 & 0.144 & 0.066 & 0.051 & 0.016 \\
10 & & 0.017 & 0.001 & & 0.003 & 0.086 & 0.002 & 0.055 \\
11 & & 0.013 & 0.020 & & 0.016 & 0.018 & 0.007 & 0.070 \\
12 & & 0.020 & 0.012 & & 0.003 & & & \\
13 & & 0.003 & 0.071 & & 0.140 & & & \\
14 & & & 0.013 & & 0.008 & & & \\
15 & & & 0.007 & & 0.003 & & & \\
16 & & & 0.004 & & & & & \\
$\mathrm{~N}$ & 320 & 317 & 331 & 341 & 176 & 212 & 191 & 176 \\
$\mathrm{H}_{\mathrm{e}}$ & 0.42 & 0.80 & 0.76 & 0.83 & 0.84 & 0.86 & 0.80 & 0.83 \\
$\mathrm{H}_{\mathrm{o}}$ & 0.37 & 0.83 & 0.73 & 0.80 & 0.81 & 0.85 & 0.80 & 0.79 \\
$\mathrm{~F}_{\mathrm{IS}}$ & 0.12 & -0.04 & 0.03 & 0.04 & 0.03 & 0.02 & -0.01 & 0.05 \\
\hline & & & & & & & & \\
\hline
\end{tabular}

system and pollen dispersal estimation (Austerlitz \& Smouse 2002, Ritland 2002).

AdUlt GENETIC STRUCTURE.-The fixation index ( $\left.\mathrm{F}_{\mathrm{IS}}\right)$ of $C$. guianensis adult trees was 0.029 and the value of $S p$ was 0.0045 (0.0024). This very weak level of SGS was, nevertheless, statistically significant with the permutation test at the 0.05 level.

POLLEN DISPERSAL.-The global estimate of pollen pool differentiation $\left(\phi_{\mathrm{FT}}\right)$ was 0.053 for $C$. guianensis with a $95 \% \mathrm{CI}$ of $0.027-$ 0.074, and 0.064 (95\% CI: 0.017-0.088) for S. rubra. Both values are significantly greater than 0 , indicating significant substructure of pollen pool allele frequencies. These global estimates of $\phi_{\text {FT }}$ yield estimates of effective number of fathers per seed parent $\left(\mathrm{N}_{\mathrm{ep}}\right)$ of 9.4 (6.8-18.5) for C. guianensis, and of 7.8 (5.7-29.4) for S. rubra.

The results for the mean pollen dispersal distance $(\delta)$ based on global estimates of $\phi_{\mathrm{FT}}$ are presented in Table 2. Using the estimated density of trees above $30 \mathrm{~cm} \mathrm{DBH}$ in size $\left(d_{\max }\right)$, and assuming the normal model of pollen dispersal, we estimated $\delta$ at $69 \mathrm{~m}(58-96$ $\mathrm{m})$ for C. guianensis and $86 \mathrm{~m}(74-167 \mathrm{~m})$ for $S$. rubra. Using the estimated minimum effective density $\left(d_{\min }\right), \delta$ is estimated at $218 \mathrm{~m}$ (184-288 m) for C. guianensis and $271 \mathrm{~m}(233-448 \mathrm{~m})$ for S. rubra. Assuming the exponential model, we obtained slightly larger values of $78 \mathrm{~m}(66-109 \mathrm{~m})$ for C. guianensis and $97 \mathrm{~m} \mathrm{(83-}$ $188 \mathrm{~m}$ ) for $S$. rubra using $d_{\max }$, compared with $244 \mathrm{~m}(207-317 \mathrm{~m})$ for $C$. guianensis and $303 \mathrm{~m}(262-491 \mathrm{~m})$ for $S$. rubra using $d_{\min }$. Overall, both species have similar levels of pollen dispersal that are influenced more by the estimate of density than by the dispersal model assumed.

The results of the pairwise estimates of $\phi_{\mathrm{FT}}$ are presented in Table 3. Overall, these results are similar to those derived from the global $\phi_{\mathrm{FT}}$ estimates, with estimates of $\delta$ varying between 71 and $355 \mathrm{~m}$ for C. guianensis, and between 81 and $287 \mathrm{~m}$ for S. rubra. The joint estimation of density and dispersal distance suggests that the effective density of reproducing individuals is lower than the estimated field density for both species—approximately an order of magnitude lower than the true density of reproductive trees in

TABLE 2. Mean pollen dispersal distance $(\delta)$ under the normal and exponential dispersal models using maximum and minimum estimates of the effective density of reproductive trees $\left(d_{\max }\right.$ and $\left.d_{\min }\right)($ trees/ha) based on global estimates of pollen pool differentiation in Carapa guianensis and Sextonia rubra.

\begin{tabular}{lcccc}
\hline $\begin{array}{l}\text { Dispersal } \\
\text { model }\end{array}$ & $\begin{array}{c}\text { Carapa guianensis } \\
\delta(\mathrm{m})(95 \% \mathrm{CI})^{\mathrm{a}}\end{array}$ & $\begin{array}{c}\text { Sextonia rubra } \\
\delta(\mathrm{m})\end{array}$ & $(95 \% \mathrm{CI})$ \\
\hline & $d_{\max }=2.50$ & $d_{\min }=0.25$ & $d_{\max }=1.30$ & $d_{\min }=0.13$ \\
\hline Normal & $69(58-96)$ & $218(184-288)$ & $86(74-167)$ & $271(233-448)$ \\
Exponential & $78(66-109)$ & $244(207-317)$ & $97(83-188)$ & $303(262-491)$ \\
\hline
\end{tabular}

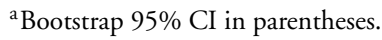


TABLE 3. Mean pollen dispersal distance ( $\delta$ ) based on pairwise pollen pool differentiation estimates for Carapa guianensis and Sextonia rubra. The density of reproductive trees (d) was constrained or estimated jointly with $\delta$ for different dispersal models. The error indicates the level of departure of the observed pairwise estimates to the dispersal model fitted.

\begin{tabular}{|c|c|c|c|c|}
\hline \multicolumn{5}{|l|}{ Carapa guianensis } \\
\hline \multirow[b]{2}{*}{ Dispersal model } & \multirow[b]{2}{*}{ Error } & \multicolumn{2}{|c|}{$\mathrm{d}$ (trees/ha) } & \multirow{2}{*}{$\frac{\delta(\mathrm{m})}{\text { Estimated }}$} \\
\hline & & Constrained & Estimated & \\
\hline Normal & 2.129 & 2.50 & & 71 \\
\hline Normal & 2.063 & & 0.23 & 218 \\
\hline Exponential & 2.127 & 2.50 & & 80 \\
\hline Exponential & 2.062 & & 0.18 & 276 \\
\hline Exponential power ${ }^{\mathrm{a}}$ & 2.127 & 2.50 & & 91 \\
\hline Exponential power ${ }^{\mathrm{b}}$ & 2.062 & & 0.13 & 355 \\
\hline Exponential power ${ }^{c}$ & 2.062 & & 0.14 & 338 \\
\hline \multicolumn{5}{|l|}{ Sextonia rubra } \\
\hline & & \multicolumn{2}{|c|}{$\mathrm{d}($ trees $/ \mathrm{ha})$} & $\delta(\mathrm{m})$ \\
\hline Dispersal model $^{\mathrm{d}}$ & Error & Constrained & Estimated & Estimated \\
\hline Normal & 0.263 & 1.30 & & 81 \\
\hline Normal & 0.228 & & 0.14 & 231 \\
\hline Exponential & 0.264 & 1.30 & & 92 \\
\hline Exponential & 0.229 & & 0.11 & 287 \\
\hline
\end{tabular}

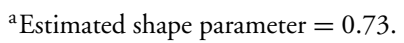

${ }^{\mathrm{b}}$ Shape parameter constrained to 0.73 .

${ }^{\mathrm{c}}$ Estimated shape parameter $=0.77$.

${ }^{\mathrm{d}}$ The exponential power model was not applicable (see results for details).

the population. For $C$. guianensis, the exponential power model of pollen dispersal provides the best fit to the observed data. The joint estimation of the three parameters gave a shape parameter of 0.77 (indicating that the dispersal curve is more fat-tailed than an exponential distribution), an estimated effective density of 0.14 trees/ha, and a mean pollen dispersal distance of $338 \mathrm{~m}$. For $S$. rubra, the best fit is the normal model, which gave an estimated effective density of 0.14 trees/ha, and a mean pollen dispersal distance of $231 \mathrm{~m}$. The program failed to converge in the case of the exponential power model in the case of S. rubra, possibly because of the reduced data set for this species. The $95 \%$ CI on the normal model parameters jointly estimated by the pairwise analysis were large, with $\delta$ (43514) $\mathrm{m}$ and $d(8.2-0.018)$ tree/ha for C. guianensis, and $\delta(49-460)$ $\mathrm{m}$ and $d(3.1-0.024)$ tree/ha for $S$. rubra.

MATING SYSTEM.-The results of the population level mating system analyses are presented in Table 4. Similar results were obtained for both species. The multi-locus outcrossing rate was estimated at 0.918 for $C$. guianensis and at 0.945 for $S$. rubra. Both values are significantly less than 1.0 , suggesting that these species are able to
TABLE 4. Mating system estimates for Carapa guianensis and Sextonia rubra, where $t_{m}$ represents the multi-locus outcrossing rate, $t_{s}$ the single-locus outcrossing rate, and $r_{p}$ the multi-locus correlation of outcrossed paternity.

\begin{tabular}{lll}
\hline Mating system parameters & Carapa guianensis & Sextonia rubra \\
\hline $\mathrm{t}_{\mathrm{m}}(\mathrm{SE})$ & $0.918^{\mathrm{a}}(0.033)$ & $0.945^{\mathrm{a}}(0.022)$ \\
$\mathrm{t}_{\mathrm{s}}(\mathrm{SE})$ & $0.902^{\mathrm{a}}(0.038)$ & $0.941(0.042)$ \\
$\mathrm{t}_{\mathrm{m}}-\mathrm{t}_{\mathrm{s}}(\mathrm{SE})$ & $0.015(0.015)$ & $0.004(0.026)$ \\
$\mathrm{r}_{\mathrm{p}}(\mathrm{SE})$ & $0.089^{\mathrm{b}}(0.024)$ & $0.096^{\mathrm{b}}(0.035)$ \\
\hline
\end{tabular}

${ }^{\mathrm{a}}$ Less than 1.000 at 5 percent level.

${ }^{\mathrm{b}}$ Greater than 0.001 at 5 percent level.

self-fertilize. We did not detect any significant levels of biparental inbreeding in either species, as measured by the difference between multi- and single-locus estimates. The estimated multi-locus correlation of paternity was low for both species, but significantly different to 0 .

The impact of local variation in density of neighbors on the mating system is presented in Table 5. For both species, we found modest variation in the density of conspecific neighbors within pollination neighborhood of individual mother trees, with values between 1.8 and 3.2 neighbors/ha for $C$. guianensis, and between 0.5 and 2.6 neighbors/ha for $S$. rubra. When the mother trees were classified into two groups of lower and higher neighbor density, C. guianensis had a mean of $2.2(N=16)$ and 2.8 neighbors/ha $(N=17)$, respectively, while $S$. rubra had a mean of $1.0(N=8)$ and 2.6 neighbors/ha $(N=10)$. When estimating mating system parameters separately for those two groups, we found no evidence for an impact of neighbor density on inbreeding levels. The estimates of outcrossing rate, level of biparental inbreeding, and correlation of paternity for both species were not significantly different between the groups ( 0.05 level). For $S$. rubra, the correlation of paternity was only marginally higher for mother trees with lower local density of neighbors compared to trees with higher local density of neighbors.

TABLE 5. Impact of variation in local density of conspecific neighbors on the mating system of Carapa guianensis and Sextonia rubra, where $t_{m}$ represents the multi-locus outcrossing rate, $t_{s}$ the single-locus outcrossing rate, and $r_{p}$ the multi-locus correlation of outcrossed paternity.

\begin{tabular}{lrrrrr}
\hline & \multicolumn{2}{c}{ Carapa guianensis } & & \multicolumn{2}{c}{ Sextonia rubra } \\
\cline { 2 - 3 } Local density $^{\mathrm{a}}$ & Low density & High density & & Low density & High density \\
\hline $\mathrm{t}_{\mathrm{m}}(\mathrm{SE})$ & $0.92(0.06)$ & $0.93(0.04)$ & & $0.95(0.09)$ & $0.90(0.02)$ \\
$\mathrm{t}_{\mathrm{s}}(\mathrm{SE})$ & $0.93(0.07)$ & $0.90(0.05)$ & & $0.88(0.09)$ & $0.92(0.03)$ \\
$\mathrm{t}_{\mathrm{m}}-\mathrm{t}_{\mathrm{s}}(\mathrm{SE})$ & $-0.02(0.02)$ & $0.02(0.03)$ & & $0.07(0.08)$ & $-0.02(0.03)$ \\
$\mathrm{r}_{\mathrm{p}}(\mathrm{SE})$ & $0.11(0.08)$ & $0.05(0.02)$ & & $0.19(0.18)$ & $0.03(0.05)$ \\
\hline
\end{tabular}

${ }^{a}$ Mother trees are classified into two groups of low and high mean number of neighbors/ha (see text for details). 


\section{DISCUSSION}

POLLEN DISPERSAL.-We found low pollen pool differentiation and high levels of pollen dispersal for both $C$. guianensis and $S$. rubra, with estimates of average pollination distances $(\delta)$ varying between $\sim 70 \mathrm{~m}$ and $\sim 350 \mathrm{~m}$. This suggests that trees in both species mate with a large number of conspecifics, distributed over a large area in their vicinity, despite (or owing to) the large distances separating conspecifics in tropical forests. The pollen dispersal distance estimates from this study appear larger than other high-density (i.e., $>10$ trees/ha) tropical trees found in similar habitats, such as Symphonia globulifera (Degen et al. 2004), and also larger than high-density tropical species with different ecological requirements, such as Gliricidia sepium (Dawson et al. 1997) and Cordia alliodora (Boshier et al. 1995). On the other hand, the pollen dispersal distances in C. guianensis and S. rubra are similar to other tropical tree species in continuous undisturbed rain forest, commonly found at low density (i.e., <1 tree/ha), such as Dinizia excelsa (Dick et al. 2003), Swietenia humilis (White et al. 2002), or Neobalanocarpus heimii (Konuma et al. 2000). This comparison of our results to previous studies adds support to the hypothesized negative relationship between population density and gene dispersal, and suggests that density variation below $\sim 5$ trees/ha may not have a strong impact on the mean distance of pollen dispersal, and that other factors related to the reproductive biology of the tree species may be more important.

It is worth noting that our estimates of pollen dispersal distances, which represent "ongoing" dispersal, are substantially lower than "historical" estimates of gene dispersal distances derived from the observed level of SGS among adult trees. For S. rubra, the historical estimate of gene dispersal was between $728 \mathrm{~m}$ and $848 \mathrm{~m}$ (Hardy et al. 2006), while even higher estimates may be expected for $C$. guianensis since its SGS is weaker than $S$. rubra. This suggests that the contribution of seed dispersal to global gene flow may be significant, at least for $S$. rubra, whose seeds are potentially dispersed by birds. Moreover, at least for $C$. guianensis, whose seed are unlikely to be dispersed at large distances at the study site, this suggests that gene dispersal estimated from a single episode of reproduction (e.g., this study) is more restricted than the cumulative effect of gene flow over hundreds of years, as measured by indirect estimates of historical gene dispersal based on SGS. In other words, ecological time-scale estimates of gene dispersal, such as obtained in our study, may be lower simply because they measure a different parameter, with different effective density perhaps, than historical estimates of gene dispersal based on levels of SGS among adults.

Among the assumptions required to estimate pollen dispersal distances using the TwoGener algorithm (see also Hardy et al. [2004] for a discussion of additional aspects), the two that have potential to bias estimates are the pollen dispersal model and the tree density used. For instance, models with a thin-tailed dispersal curve (e.g., the normal model) may result in the underestimation of the true dispersal distances in cases when the actual pollen dispersal curve is fat-tailed. However, estimates of $\delta$ that assume different dispersal models are actually quite similar (Tables 2 and 3), suggesting that any bias introduced by these assumptions may be low.
In comparison, the assumed tree density has a significant impact on $\delta$ estimates. Since some trees in the population may be more successful than others at pollinating their neighbor flowers, simply using trees above $30 \mathrm{~cm} \mathrm{DBH}$ to estimate density may lead to an overestimate of the effective tree density, and an underestimate of mean pollen dispersal distances (Austerlitz \& Smouse 2002). For that reason, we have estimated $\delta$ : (1) with global $\phi_{\mathrm{FT}}$ using maximal $\left(d_{\max }\right)$ and minimal $\left(d_{\min }\right)$ estimates of the effective population density, providing, respectively, lower and upper bound estimates of pollen dispersal distance; and (2) with pairwise $\phi_{\mathrm{FT}}$ to jointly infer density and dispersal distance.

The joint estimation revealed that the effective density of reproducing trees was about one-tenth that of the estimated field density of trees. This is among the smallest $\mathrm{N}_{\mathrm{e}} / \mathrm{N}$ ratios observed in plant populations (Frankham 1995). However, the $95 \%$ CI estimated for the effective density estimates were very large (i.e., between about 8 and 0.02 trees/ha for both species), reflecting the fact that data sets larger than ours are needed to estimate $d$ precisely (Austerlitz $\&$ Smouse 2002). Nonetheless, the low estimated $d$ likely indicates that there is variation in male reproductive success in our populations. Treecrown observations to determine which individuals were flowering in a sample of $C$. guianensis trees in 2003, and $S$. rubra trees in 2002, revealed that about 75 percent of trees above $30 \mathrm{~cm} \mathrm{DBH}$ at the flowering peak had the potential to exchange pollen (Dendrogene project for C. guianensis, M. Kanashiro, pers. comm.; D. Cloutier and O. Hardy for S. rubra, pers. obs.), which suggests that some sampled trees were not perfectly synchronized with the population. Paternity analyses of animal-pollinated tropical trees (e.g., Konuma et al. 2000) also revealed some asymmetry among pollen contributors to a single mother, which could not be explained by "isolation by distance" alone. Other factors, such as variation in the number of male gametes produced by each pollen donor, may play an additional role in fertility variation if there are differences in tree size and/or access to light.

MATING SYSTEM.- The high outcrossing rates found in this study $\left(t_{m}>90 \%\right)$ fall within the range of typical values estimated for tropical tree populations (Loveless 2002). Some significant, but low, selfing levels were detected in this study, as in other studies of tropical tree populations (Loveless 2002), suggesting that C. guianensis and $S$. rubra are able to self-fertilize. It is worth noting that because of the potential presence of inbreeding depression, the observed level of selfing may depend on the developmental stage at which the progenies are analyzed. Thus, we may have underestimated the level of self-fertilization for both species because we measured inbreeding levels in the seeds (for C. guianensis) or in the seedlings (for S. rubra), i.e., after early acting inbreeding depression may have selected out some inbred progeny. Our results nevertheless reinforce the perception of a predominance of outcrossing in tropical tree mating systems that has developed over the past three decades (Loveless 2002, Ward et al. 2005).

When inferring levels of biparental inbreeding from differences between single- and multi-locus estimate of outcrossing rate (Ritland 2002), we do not detect any significant levels of biparental inbreeding in our populations. In the case of $S$. rubra, this result 
may be due to the small data set we used for the estimation, as another study reported significant levels of biparental inbreeding for this species (Veron et al. 2005). Weak levels of biparental inbreeding could be interpreted as a consequence of extensive pollen flow in these populations, and weak genetic structure among reproducing trees, since opportunities for mating among near-neighbor relatives in such a situation may be infrequent.

We estimated the correlation of paternity at less than 0.1 in both C. guianensis and $S$. rubra. This indicates that the seed crop of individual trees is composed mostly of half-sibs. For both species, the values of correlation of paternity are approximately two times the values of $\phi_{\mathrm{FT}}$, reflecting the fact that these statistics estimate the same quantity (Hardy et al. 2004). In the case of tropical trees, which are mostly animal-pollinated, we might expect varying levels of correlated paternity depending on the reproductive biology of the species, but most tropical rain forest trees studied to date show a pattern of low correlated paternity (e.g., Doligez \& Joly 1997). The large pool of potential pollen donors inferred for $C$. guianensis and $S$. rubra likely explains the low level of correlated paternity observed in these species.

Assuming pollinator behavior follows an optimal cost/benefit foraging strategy, reduced density of flowering trees has been hypothesized to increase levels of inbreeding (Murawski \& Hamrick 1991, 1992; Murawski et al. 1994). We found no evidence, however, for an impact of local density of neighbors on mating system parameters within our populations. Moreover, applying a different approach (Hardy et al. 2004) which estimates correlated paternity for each mother tree and regresses this value on local density, again we found no significant impact of local density on the correlation of paternity (D. Cloutier, pers. obs.). This could be partly explained by the scale of effective pollen dispersal, and by the relative abundance of conspecifics for C. guianensis and S. rubra compared to other tree species found in the same sites. For both species, we found extensive pollen dispersal, i.e., beyond the distances separating the mother trees to their immediate near-neighbors. Since the mother trees are pollinated by a large pool of potential pollen donors distributed over a large area, local variation in neighbor density within pollination neighborhood may be smoothed out, and thus may be insufficient to have significant consequences on variation in the outcrossing rate. On the other hand, the correlation of paternity seemed to be more influenced by variation in conspecific density, but consequences on inbreeding levels appear to be marginal at best. In the case of $S$. rubra, the small data set and the lack of information about the density of conspecifics in between the plots at Paracou also limited our ability to detect any impact of neighbor density on inbreeding levels in the first place.

Comparisons of our results with other studies on C. guianensis and S. rubra may also help to detect potential mating system consequences associated with population density. An allozyme study in Costa Rican populations of C. guianensis with more than 10 trees/ha revealed high outcrossing rates (0.97-0.99; Hall et al. 1994). Another microsatellite study in the same area, based on adult and sapling genotypes, found that the population is completely outcrossed (Dayanandan et al. 1999). Comparison of our Amazonian low-density population to the Costa Rican high-density populations suggests that higher outcrossing rates may be favored by an increase in population density. In other studies, there was no evidence for reduced inbreeding in high-density populations of the Neotropical S. globulifera in French Guiana (Degen et al. 2004) compared to lower density populations in Panama (Stacy et al. 1996). Furthermore, a genetic study of $S$. rubra seeds at Paracou, collected 2 yr after those analyzed in this study, revealed similar levels of pollen dispersal, but slightly higher outcrossing rate (0.99) with significant levels of biparental inbreeding (Veron et al. 2005), despite having the same field population density between the $2 \mathrm{yr}$. The limited precision of estimates obtained from genetic data may explain some of the differences between studies, but also these differences suggest that tree density is not the only factor influencing the mating system, and that nonoverlapping phenologies, variation in pollen production among trees, and variation in the composition and the behavior of the animal pollinators might play an important role. It appears that only large changes in population density, such as a tenfold increase or decrease, could have significant mating system consequences. This also suggests that for tree species that have relatively dense populations and are pollinated by small insects, minor changes in population density (e.g., as when a small proportion of trees are exploited for timber) may not result in significant population genetic impacts.

To conclude, the two Amazonian tree species investigated here produce genetically diverse seed crops in their natural settings, have high levels of pollen flow, and minimal levels of inbreeding. However, variation in local density of neighbors within pollination neighborhood did not have a significant impact on inbreeding levels in the populations investigated here. The mating system and pollen flow parameters estimated in this study are strikingly similar for these two timber species with high population density and pollinated by small insects, but having different sexual systems that do not completely prevent selfing. These results, while adding support to the emerging paradigm that tropical trees have evolved in a context of regular outcrossing with distant individuals, also suggest that tropical tree populations pollinated by small insects can bypass near-neighbor mating, not only in low density populations (Stacy et al. 1996), but also for medium-to-high density populations such as those examined here.

\section{ACKNOWLEDGMENTS}

We thank IBAMA and CIRAD-Forêt for access to the experimental sites. We thank Jaboury Ghazoul and the two reviewers for their suggestions to improve the manuscript, as well as I. S. Thompson, J. Campolina, inhabitants of comunidade Branco-1 km 83 and Belterra, V. C. R. Azevedo, T. N. Almeida, V. P. da Silva, M. S. Borges, F. Carneiro, E. Bandou, S.-O. Cazal, V. Troispoux for their help during field and lab activities. This study is part of Dendrogene Project: Genetic Conservation in Managed Forests in Amazônia (2000-2004, www.cpatu.embrapa.br/dendro/index.htm) carried out by Embrapa Amazônia Oriental and its partners, within bilateral 
cooperation between Brazil and United Kingdom, through Brazilian Cooperation Agency (ABC) and Department for International Development (DFID). This work was carried out with the aid of a grant from the International Development Research Center, Ottawa, Canada (www.idrc.ca). D. Schoen acknowledges support from an NSERC Discovery Grant. The Fonds Nature et Technologies, Québec (FQRNT), Natural Sciences and Engineering Council, Canada (NSERC), and the Organization of American States (OAS) provided financial support to D. Cloutier.

\section{LITERATURE CITED}

Austerlitz, F., C. W. Dick, C. Dutech, E. K. Klein, S. Oddou-Muratorio, P. E. SMOUSE, AND V. L. SORK. 2004. Using genetic markers to estimate the pollen dispersal curve. Mol. Ecol. 13: 937-954.

Austerlitz, F., AND P. E. SmOusE. 2001. Two-generation analysis of pollen flow across a landscape. II. Relation between Phi(ft), pollen dispersal and interfemale distance. Genetics 157: 851-857.

AusterlitZ, F., AND P. E. SMOUSE. 2002. Two-generation analysis of pollen flow across a landscape. IV. Estimating the dispersal parameter. Genetics 161: 355-363.

BAKER, H. G. 1959. Reproductive methods as factors in speciation in flowering plants. Cold Spring Harb. Symp. Quant. Biol. 24: 177-191.

BAWA, K. S. 1974. Breeding systems of tree species of a lowland tropical community. Evolution 28: 85-92.

BAWA, K. S. 1990. Plant-pollinator interactions in tropical rain-forests. Ann. Rev. Ecol. Syst. 21: 399-422.

BaWa, K. S., S. H. Bullock, D. R. Perry, R. E. Coville, and M. H. Grayum. 1985. Reproductive biology of tropical lowland rainforest trees. II. Pollination systems. Am. J. Bot. 72: 346-356.

Boshier, D. H., M. R. Chase, and K. S. Bawa. 1995. Population genetics of Cordia alliodora (Boraginaceae), a Neotropical tree. 3. Gene flow, neighborhood, and population substructure. Am. J. Bot. 82: 484490.

BRown, A. H. D., AND R. W. Allard. 1970. Estimation of the mating system in open-pollinated maize populations using isozyme polymorphisms. Genetics 66: 133-145.

Chase, M. R., C. Moller, R. Kesseli, and K. S. Bawa. 1996. Distant gene flow in tropical trees. Nature 383: 398-399.

Cloutier, D., J. S. R. Povoa, L. C. Procopio, N. V. M. Leao, L. H. O. WADT, A. Y. CIAMPI, AND D. J. SCHOEN. 2005. Chloroplast DNA variation of Carapa guianensis in the Amazon basin. Silvae Genet. 54: 270274.

Dayanandan, S., J. Dole, K. Bawa, and R. Kesseli. 1999. Population structure delineated with microsatellite markers in fragmented populations of a tropical tree, Carapa guianensis (Meliaceae). Mol. Ecol. 8: 15851592.

Dawson, I. K., R. Waugh, A. J. Simons, and W. Powell. 1997. Simple sequence repeats provide a direct estimate of pollen-mediated gene dispersal in the tropical tree Gliricidia sepium. Mol. Ecol. 6: 179183.

Degen, B., E. BANDOU, AND H. CARON. 2004. Limited pollen dispersal and biparental inbreeding in Symphonia globulifera in French Guiana. Heredity 93: 585-591.

DICK, C. W. 2001. Genetic rescue of remnant tropical trees by an alien pollinator. Proc. R. Soc. Lond. B. 268: 2391-2396.

Dick, C. W., G. ETChelecu, and F. Austerlitz. 2003. Pollen dispersal of tropical trees (Dinizia excelsa: Fabaceae) by native insects and African honeybees in pristine and fragmented Amazonian rainforest. Mol. Ecol. 12: 753-764.

DoligeZ, A., AND H. I. Joly. 1997. Mating system of Carapa procera (Meliaceae) in the French Guiana tropical forest. Am. J. Bot. 84: 461-470.
FEDEROV, A. A. 1966. Structure of tropical rain forest and speciation in humid tropics. J. Ecol. 54: 1-11.

FrankHAM, R. 1995. Effective population size/adult population size ratios in wildlife—a review. Genet. Res. 66: 95-107.

Guariguata, M. R., H. Arias-LeClaire, and G. Jones. 2002. Tree seed fate in a logged and fragmented forest landscape, northeastern Costa Rica. Biotropica 34: 405-415.

Hall, P., L. C. OrRell, and K. S. BaWA. 1994. Genetic diversity and mating system in a tropical tree, Carapa guianensis (Meliaceae). Am. J. Bot. 81: 1104-1111.

HaRdY, O. J., AND X. VEKEMANS. 2002. SPAGEDI: A versatile computer program to analyse spatial genetic structure at the individual or population levels. Mol. Ecol. Notes 2: 618-620.

Hardy, O. J., S. C. GonZalez-Martinez, B. Colas, H. Freville, A. Mignot, AND I. OLIVIERI. 2004. Fine-scale genetic structure and gene dispersal in Centaurea corymbosa (Asteraceae). II. Correlated paternity within and among sibships. Genetics 168: 1601-1614.

Hardy, O. J., L. Maggia, E. Bandou, P. Breyne, H. Caron, M-H. Chevallier, A. Doligez, C. Dutech, A. Kremer, C. LatoucheHalle, V. Troispoux, V. Veron, and B. Degen. 2006. Fine-scale genetic structure and gene dispersal inferences in 10 Neotropical tree species. Mol. Ecol. 15: 559-571.

Kanashiro, M., I. S. Thompson, J. A. G. Yared, M. D. Loveless, P. Coventry, R. C. V. Martins-Da-Silva, B. Degen, and W. AMARAL. 2002. Improving conservation values of managed forests: The Dendrogene Project in the Brazilian Amazon. Unasylva 53: 2533.

Konuma, A., Y. Tsumura, C. T. Lee, S. L. LeE, and T. OKuda. 2000. Estimation of gene flow in the tropical-rainforest tree Neobalanocarpus heimii (Dipterocarpaceae), inferred from paternity analysis. Mol. Ecol. 9: 1843-1852.

LEDIG, F. T. 1992. Human impacts on genetic diversity in forest ecosystems. Oikos 63: 87-108.

Loveless, M. D. 2002. Genetic diversity and differentiation in tropical trees. In B. Degen, M. D. Loveless, and A. Kremer (Eds.). Modelling and experimental research on genetic processes in tropical and temperate forests (2000 : Kourou, French Guiana), pp. 3-30. Embrapa Amazonia Oriental, Belem, Brazil.

Murawski, D. A., I. GunatilleKe, AND K. S. BaWA. 1994. The effects of selective logging on inbreeding in Shorea megistophylla (Dipterocarpaceae) from Sri-Lanka. Conserv. Biol. 8: 997-1002.

Murawski, D. A., AND J. L. Hamrick. 1991. The effect of the density of flowering individuals on the mating systems of 9 tropical tree species. Heredity 67: 167-174.

MurawsKi, D. A., AND J. L. Hamrick. 1992. The mating system of Cavanillesia platanifolia under extremes of flowering-tree density-A test of predictions. Biotropica 24: 99-101.

NASON, J. D., AND J. L. HAMRICK. 1997. Reproductive and genetic consequences of forest fragmentation: Two case studies of Neotropical canopy trees. J. Hered. 88: 264-276.

Raymond, M., And F. Rousset. 1995. GENEPOP (version 1.2) Population genetics software for exact tests and ecumenicism. J. Hered. 86: 248249.

RITLAND, K. 2002. Extensions of models for the estimation of mating systems using $\mathrm{n}$ independent loci. Heredity 88: 221-228.

Scarano, F. R., T. S. Pereira, and G. Rocas. 2003. Seed germination during floatation and seedling growth of Carapa guianensis, a tree from floodprone forests of the Amazon. Plant Ecol. 168: 291-296.

Schmitt, L., And M. Bariteau. 1988. Gestion de l'ecosysteme forestier guyanais: Etude de la croissance et de la regeneration naturelle: Dispositif de Paracou. Bois et Forets des Tropiques 220: 324.

Smouse, P. E., R. J. Dyer, R. D. Westfall, and V. L. Sork. 2001. Twogeneration analysis of pollen flow across a landscape. I. Male gamete heterogeneity among females. Evolution 55: 260-271. 
Stacy, E. A., J. L. Hamrick, J. D. Nason, S. P. Hubbell, R. B. Foster, AND R. CONDIT. 1996. Pollen dispersal in low-density populations of three Neotropical tree species. Am. Nat. 148: 275298.

Vekemans, X., AND O. J. Hardy. 2004. New insights from fine-scale spatial genetic structure analyses in plant populations. Mol. Ecol. 13: 921935.

Veron, V., H. Caron, and B. Degen. 2005. Gene flow and mating system of the tropical tree Sextonia rubra. Silvae Genet. 54: 275-280.
Vinson, C. C., V. C. R. Azevedo, I. Sampaio, and A. Y. Ciampi. 2005. Development of microsatellite markers for Carapa guianensis (Aublet), a tree species from the Amazon forest. Mol. Ecol. Notes 5: 33-34.

Ward, M., C. W. Dick, R. GRibel, AND A. J. Lowe. 2005. To self, or not to self... A review of outcrossing and pollen-mediated gene flow in Neotropical trees. Heredity 95: 246-254.

White, G. M., D. H. Boshier, AND W. Powell. 2002. Increased pollen flow counteracts fragmentation in a tropical dry forest: An example from Swietenia humilis Zuccarini. Proc. Natl. Acad. Sci. 99: 2038-2042. 